\title{
Predicted and Back-calculated Coefficients of Permeability of Randomly Fractured Rock Mass: A Case Study
}

\author{
Hisham Eid \\ heid@qu.edu.qa \\ Department of Civil and Architectural Engineering, Qatar University, Doha, Qatar \\ Barry O'Sullivan \\ bsullivan@hydroservint.com \\ Hydroserv, Doha, Qatar \\ Mohammed Elshafie \\ melshafie@qu.edu.qa \\ Department of Civil and Architectural Engineering, Qatar University, Doha, Qatar \\ Reiner Stollberg \\ r.stollberg@fugro.com \\ Fugro, Doha, Qatar \\ Robert Kalin \\ robert.kalin@strath.ac.uk \\ Department of Civil and Environmental Engineering, University of Strathclyde, the UK
}

\begin{abstract}
This paper presents the discrepancy between the coefficients of permeability measured for randomly fractured limestone using field falling-head tests and that back-calculated for the same rock mass based on the actual discharge yielded from a dewatering system designed for a typical construction site in Doha, Qatar. The study results showed that the back-calculated coefficient of permeability is outside the range of the values measured from the falling-head tests and almost seven times higher in magnitude than the fallinghead tests average. The need of having a reliable correlation that can be used to predict the actual permeability of randomly fractured rock in terms of its rock quality indices and the results of the commonly conducted field falling-head test is highlighted.
\end{abstract}

Keywords: Dewatering; Field tests; Fractured limestone; Permeability; Rock mass

\section{INTRODUCTION}

Construction dewatering is an essential activity required for many civil engineering projects. The performance of such activity is mainly dependent on the suitability of the dewatering system to the existing hydrogeological conditions and the accuracy of estimating the permeability of the matrix or material to be dewatered. Design of dewatering systems has become a major task in the construction of hundreds of infrastructure projects built as part of the very rapid and significant development of Greater Doha and along the eastern coast of Qatar. This inevitably involved dewatering of a randomly fractured limestone of Eocene age. Field falling-head permeability tests are commonly used for estimating the permeability of such limestone. This paper presents the subsurface and hydrological conditions of a construction site in Doha, the results from twenty falling-head permeability tests conducted on the site as well as the rock mass permeability that has been back-calculated from the water discharge pumped 
out of the designed dewatering system on the site. The project site is located in Lusail, approximately $15 \mathrm{Km}$ north of the centre of Doha, capital of Qatar.

\section{CASE DESCRIPTION AND SUBSURFACE CONDITIONS}

The case study presented herein involved the design of a dewatering scheme required for constructing a boulevard tunnel and associated excavation. An open excavation with width, length, and depth of $73 \mathrm{~m}, 884 \mathrm{~m}$, and $14.9 \mathrm{~m}$, respectively, was to be constructed in dry conditions. The groundwater table was encountered at a depth of $7.29 \mathrm{~m}$ below ground surface that is located at $3.50 \mathrm{~m}$ above Qatar National Height Datum (QNHD). As a result, a drawdown level of $-12.40 \mathrm{~m}$ was targeted (Fig. 1). The distance to open water (i.e., to the Gulf coast) was about $750 \mathrm{~m}$ from the edge of the excavation.

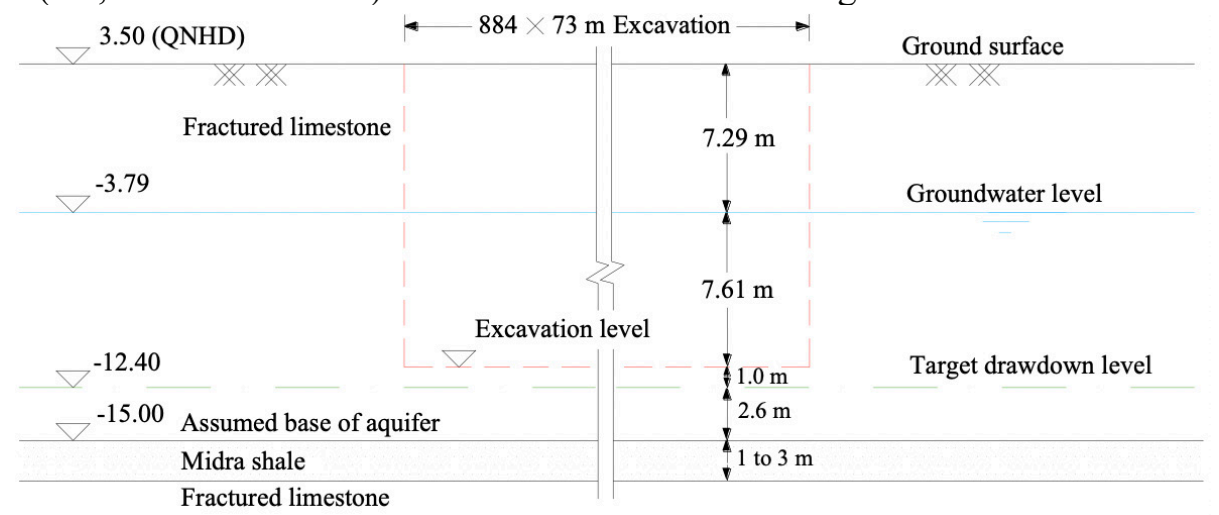

Figure 1: General profile of the dewatering scheme

The subsurface exploration program comprised the excavation of thirty two boreholes and seventeen trail pits located across the project area. Depths of boreholes ranged from $3.5 \mathrm{~m}$ to $35 \mathrm{~m}$ while the trial pits had a width of $1.5 \mathrm{~m}$ and depths ranging between 0.6 $\mathrm{m}$ and $1.2 \mathrm{~m}$. The exploration showed that the subsurface profile in the project area starts with $0.5 \mathrm{~m}$ of residual soil (typically, silty sand with some gravel and cobbles of limestone) underlain by an extended layer of fractured limestone. The limestone is frequently interrupted at depths between 18 and $20 \mathrm{~m}$ by a layer of Midra shale that varies in thickness from $1.0 \mathrm{~m}$ to $3.0 \mathrm{~m}$. Because of its low permeability, the shale acts as a confining stratum, preventing large scale vertical water movement into and out of the underlying limestone (Eid 2007). Consequently, the top of the shale layer was considered as the base of an unconfined aquifer from which water was pumped out using the dewatering system described in a subsequent section.

As indicators of the degree of rock fracturing that is related to its permeability, values of rock quality designation (RQD), solid core recovery (SCR), and total core recovery (TCR) measured in twenty four boreholes for the aquifer depth (i.e., between elevations -3.79 $\mathrm{m}$ and $-15.00 \mathrm{~m}$ QNHD) are shown in Figure 2. The three indices (RQD, SCR, and TCR) are defined in BS 5930 (1999) as the sum length of all core pieces that are $10 \mathrm{~cm}$ or longer, the length of core recovered as solid cylinders, and the total amount of core sample recovered, respectively, expressed as a percentage of the length of core run. Table 1 shows the result of a statistical analysis on these measured indices. 


\section{FIELD PERMEABILITY TESTS}

As part of the geotechnical investigation, falling-head permeability tests were carried out in selected boreholes. Dissipation tests were also carried out in some trail pits. All of these tests were performed according to the procedures described in BS 5930 (1999). The coefficient of permeability values estimated for the rock located at each fallinghead and dissipation test are shown in Figure 3. It can be seen that the wide range of the measured coefficient of permeability revokes the possibility of having one representative value. For example, the measured coefficients of permeability for fractured rock near the excavation level range between $2.1 \times 10^{-5}$ and $5.57 \times 10^{-4} \mathrm{~m} / \mathrm{sec}$ with an average value of about $1 \times 10^{-4} \mathrm{~m} / \mathrm{sec}$.

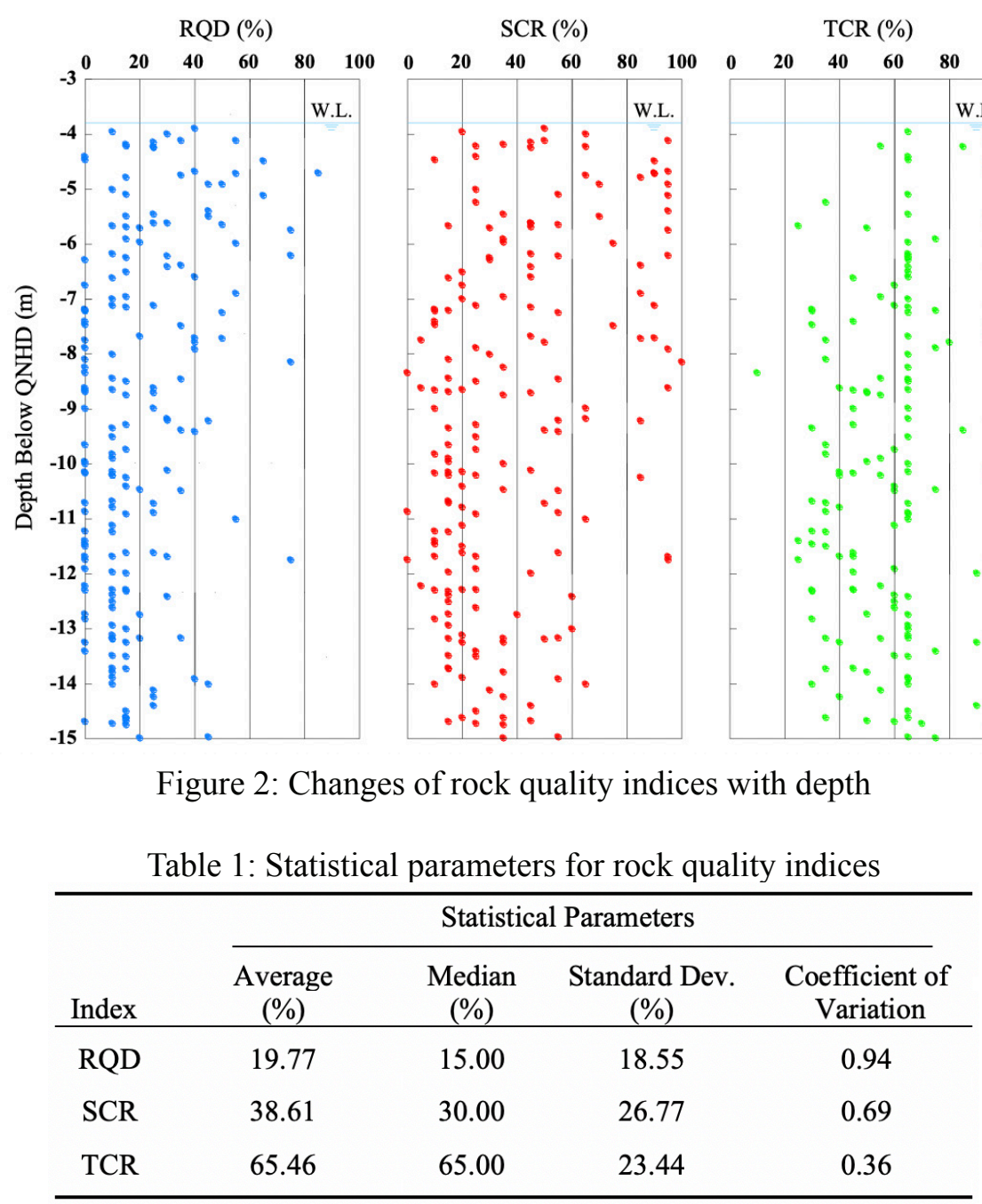




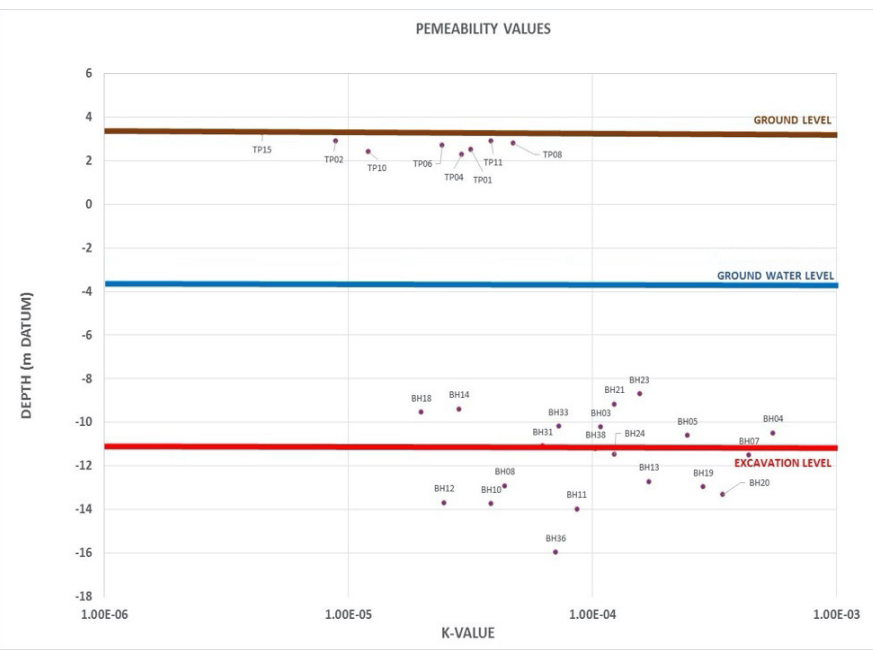

Figure 3. Coefficients of permeability of fractured rock measured in boreholes and test pits

\section{BACK-CALCULATED PERMEABILITY}

The coefficient of permeability of the rock mass in the project site was backcalculated using the water discharge pumped out of the employed dewatering system. The system consisted of 77 deep wells supplemented with a perimeter and cross trench system to achieve the required drawdown (Figure 4). The project dewatering system began operation in March 2014 and was completed by October 2015. Figure 5 shows the project site after completion of excavation.

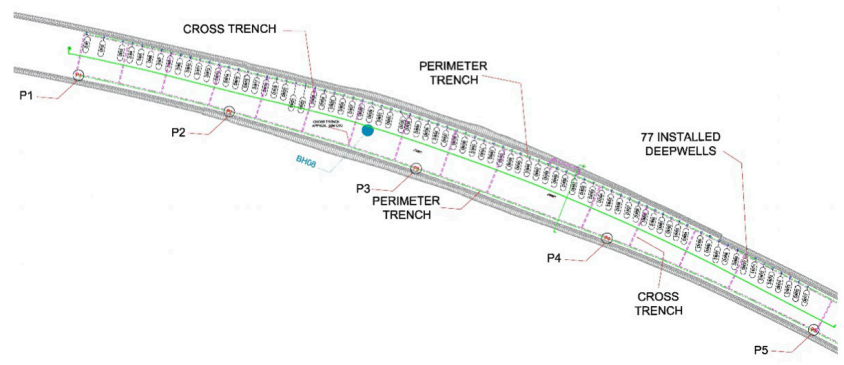

(a)

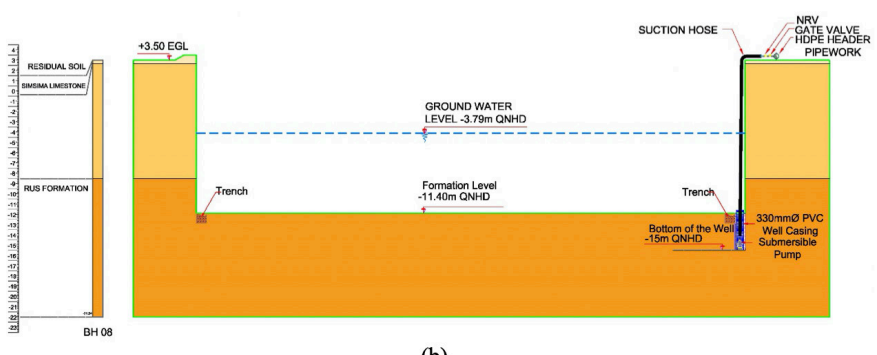

(b)

Figure 4: Schematic drawing for the excavation and the employed dewatering system: (a) plan; (b) cross section 


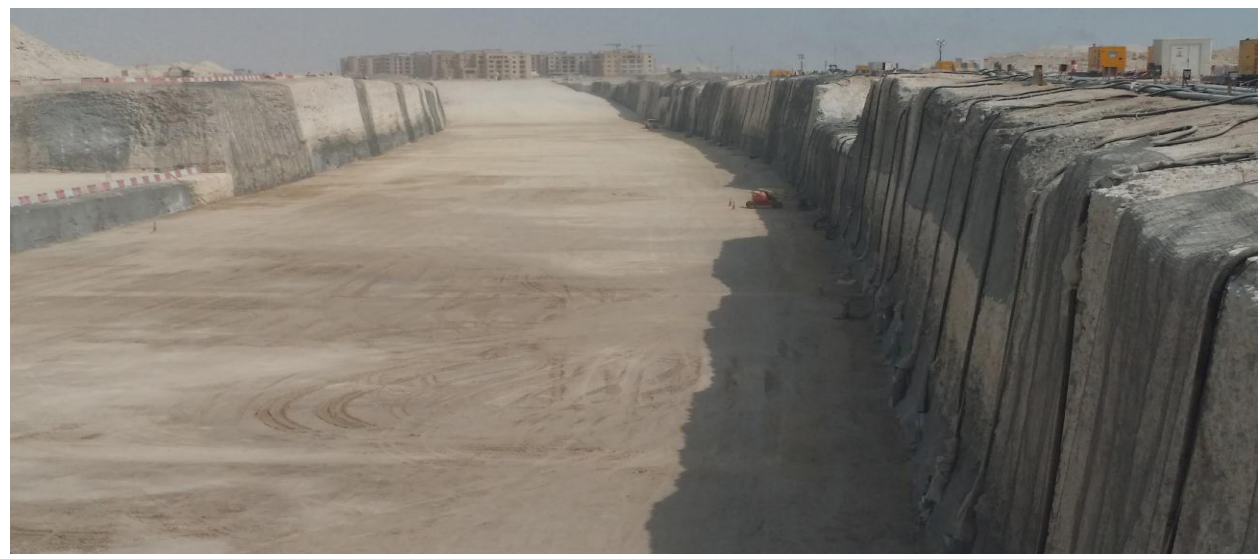

Figure 5: Completed excavation at the project site

A summary of the actual flowrate encountered is presented in Figure 6. The steadystate flow was recorded once the final excavation level was reached. This was in midDecember, 2014. Such flow rate (i.e., 465 litre $/ \mathrm{sec}$ or $0.465 \mathrm{~m}^{3} / \mathrm{sec}$ ) was used to backcalculate the coefficient of permeability of the rock mass $(k)$ utilizing the following equation for pumping an unconfined aquifer (Preene et al. 2016)

$$
Q=\frac{k x\left(H^{2}-h_{w}^{2}\right)}{L_{o}}
$$

Where $Q, x, H, h_{w}, L_{\mathrm{o}}$ are the system inflow [taken as $0.465 \mathrm{~m}^{3} / \mathrm{sec}$ ], the linear length of slot [taken as the perimeter of excavated area $=1914 \mathrm{~m}$ ], the aquifer depth [taken as $11.21 \mathrm{~m}$ ], the residual depth of aquifer [taken as $2.6 \mathrm{~m}$ ], and the radius of influence [taken $=1500\left(H-h_{w}\right)(k)^{0.5}$ as recommended by Mansur and Kaufman (1962)], respectively. This yielded a back-calculated coefficient of permeability of $6.96 \times 10^{-4} \mathrm{~m} / \mathrm{sec}$.

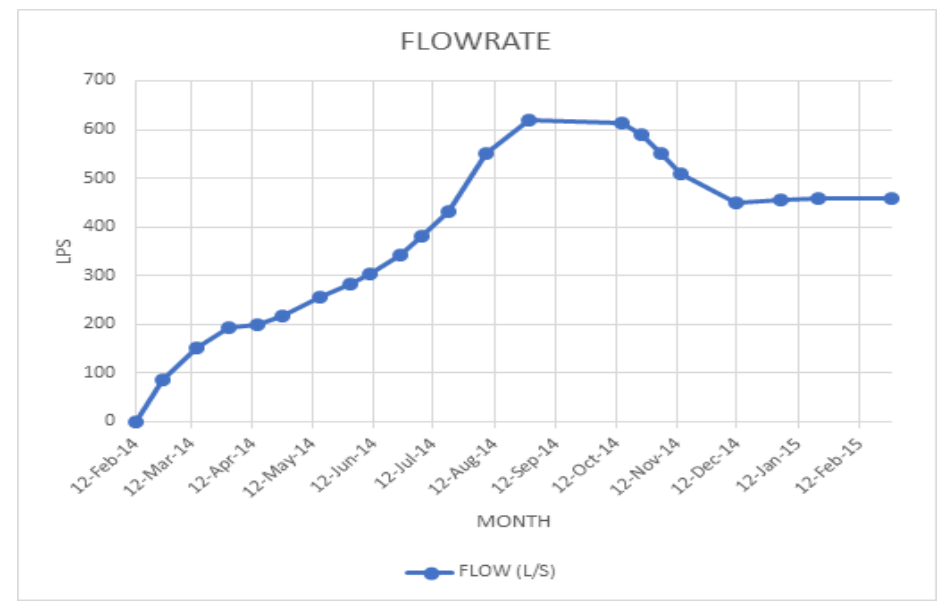

Figure 6: Change of flow rate (in litre/sec) with time 


\section{ANALYSIS AND CONCLUSION}

Considerable discrepancy can be noticed when comparing the values of the coefficient of permeability measured from the falling-head permeability tests to that back-calculated for the rock mass using the discharge pumped out of the dewatering system employed on site. The magnitude of the latter is outside the range of the measured values and almost seven times higher than their average. The studied limestone does not encompass any jointing system but is consistently and randomly fractured. The degree of such fracturing changes with depth showing a significant scatter in the measured rock quality indices (Figure 2 and Table 1). This may be contributed to the discrepancy between the measured and back-calculated coefficients of permeability for the rock mass.

The selection of permeability values is recognized as a critical impute parameter for the design of a successful dewatering scheme. Poor permeability estimates can result in large errors in the flow rate and consequently significant loss of time and money. A better estimate for the rock mass permeability can be made through conducting pumping tests. However, this occurs in rare occasions because of the relatively higher cost and longer execution times for such hydraulic tests. The common practice is to conduct a series of field falling-head permeability tests. Results of these tests frequently lead to poor estimation of the rock mass permeability as shown in the current study. To have a better technique for estimating the permeability of randomly fractured rock, considerable number of similar studies are needed. This effort could include attempts to develop a reliable relationship that correlates such permeability with the results of field fallinghead permeability tests and the commonly determined rock quality indices.

\section{ACKNOWLEDGMENT}

The funding provided by the Qatar National Research Fund (QNRF), Qatar, under Project No: NPRP12S-0314-190366, for this research work is deeply appreciated.

\section{REFERENCES}

BS 5930 (1999). Code of Practice for site investigations, British Standards.

Eid, H. T. (2007). "A technique for estimating permeability of a randomly fractured rock mass", Acta Geotechnica, Vol. 2, No. 2, pp. 97-102.

Mansur, C. I. \& Kaufman, R. I. (1962). Dewatering. In G. A. Leonards (Ed) Foundation Engineering, McGraw-Hill, New York, pp. 241-350.

Preene, M., Roberts, T. O. L., Powrie, W. \& Dyer, M. R. (2016). Groundwater control — design and practice, Second Edition, CIRIA Publication C515, London, 185 p. 